NASA

Technical Memorandum 106211

AIAA-93-2295
AVSCOM

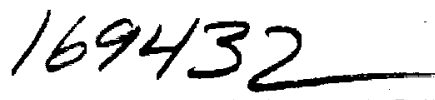

ARL-TR-171

\title{
Dynamic Analysis of Spur Gears Using Computer Program DANST
}

Fred B. Oswald

Lewis Research Center

Cleveland, Ohio

Hsiang Hsi Lin and Chuen-Huei Liou

Memphis State University

Memphis, Tennessee

and

Mark J. Valco

Propulsion Directorate

U.S. Army Research Laboratory

Lewis Research Center

Cleveland, Ohio

Prepared for the

29th Joint Propulsion Conference and Exhibit cosponsored by the AIAA, SAE, ASME, and ASEE

Monterey, California, June 28-30, 1993
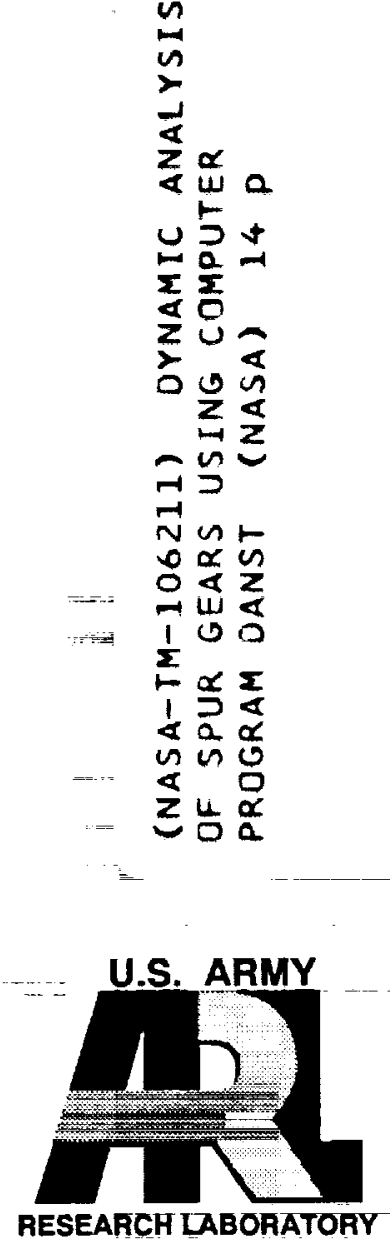
$-+--$

$-\cdots$

-- - - - - -

- -

-...

$--\cdot=$ 


\title{
DYNAMIC ANALYSIS OF SPUR GEARS USING COMPUTER PROGRAM DANST
}

\author{
Fred B. Oswald \\ National Aeronautics and Space Administration \\ Lewis Research Center \\ Cleveland, Ohip 44135
}

Hsiang Hsi Lin and Chuen-Huei Liou
Memphis State University
Memphis, Tennessee 38152

Mark J. Valco

Vehicle Propulsion Directorate

U.S. Army Research Laboratory

Lewis Research Center

Cleveland, Ohio 44135

\section{Summary}

DANST is a computer program for static and dynamic analysis of spur gear systems. The program can be used for parametric studies to predict the effect on dynamic load and tooth bending stress of spur gears due to operating speed, torque, stiffness, damping, inertia, and tooth profile.

DANST performs geometric modeling and dynamic analysis for low- or high-contact-ratio spur gears. DANST can simulate gear systems with contact ratio ranging from one to three. It was designed to be easy to use and it is extensively documented by comments in the source code.

This report describes the installation and use of DANST. It covers input data requirements and presents examples. The report also compares DANST predictions for gear tooth loads and bending stress to experimental and finite element results.

\section{Introduction}

NASA sponsored the development of several dynamic analysis codes to analyze vibration of gear transmissions. These include GEARDYN (Boyd and Pike, 1987, Pike, 1981), GRD (Geared Rotor Dynamics) (Kahraman et al., 1990, Zakrajsek, et al., 1990) and DANST (Lin et al., 1988a, 1988b, 1986).

Earlier work with DANST demonstrated how to use the program to reduce unwanted dynamic action in lowcontact-ratio gears (Lin et al., 1989a, 1989b) and in highcontact-ratio gears (Lee et al., 1991, Lin et al., 1993, Liou et al., 1992). Another study compared DANST predictions with experimental values for gear tooth load and stress (Oswald et al., 1991).

Copyright 1993 by the American Institute of Aeronautics and Astronautics, Inc. No copyright is asserted in the United States under Title 27, U.S. Code. The U.S. Government has a royalty-free license to exercise al] rights under the copyright claimed herein for Governmental purposes. All other rights are reserved by the copyright owner.
An on-disk User's Manual is included with the program and previous reports present examples, but there was no comprehensive guide to help the analyst. This report is intended to provide such a guide. It incorporates much of the User's Manual and adds test cases illustrating both input data and output plots.

\section{Program Capabilities}

Dynamic Analysis of Spur Gear Transmissions (DANST) is a computer program for spur gear systems. The program calculates the properties of system components and substitutes them into the governing equations to solve for dynamic tooth loads and tooth bending stresses.

DANST is based on a four-degree-of-freedom, lumpedmass model of a gear transmission (Fig. 1). The model includes driving and driven gears, connecting shafts, motor, and load. The equations of motion were derived from basic gear geometry and elementary vibration principles. The dynamic solution is found by integrating the equations of motion. The model and method of solution are described in several of the references (including Lin et al., 1988a, and 1986).

DANST provides the user with several options including: (1) Selection of materials, basic gear geometry, and operating conditions; (2) Various combinations of tooth profile variations (including three standard forms of tip relief) and user-digitized profile modifications; (3) The choice of static and dynamic analysis; and (4) Various printed and plotted outputs.

\section{Input Data}

The input data for DANST is submitted by lines (records) in an input data file. Most runs require 51 items in eight data lines. The input data must be entered in the order shown. Data items must be separated by one or more 
spaces or by commas. The analysis assumes that gear 1 is connected to the motor (input) and gear 2 is connected to the load (output). Variable names are given in mixed case to help suggest the meaning.

Line 1. Job Heading (1 item reqd.)

$\begin{array}{cccc}\text { Item } & \text { Variable } & \text { Data type } & \text { Description } \\ 1 \text { jobID } & \text { CHAR } & \text { Heading (up to } 60 \text { characters). }\end{array}$

Line 2. Gear Geometry Parameters (11 items reqd.).

\begin{tabular}{clll} 
Item & Variable & Data type & Description \\
\hline 1 & NT1 & INT & Number teeth on gear 1. \\
2 & NT2 & INT & Number teeth on gear 2. \\
3 & DP & REAL & Diametral Pitch, 1/in. \\
4 & phiD & REAL & Pressure angle, degrees. \\
5 & FW & REAL & Face width of teeth, in. \\
6 & BL & REAL & Tooth pair backlash, in. \\
7 & Imod & INT & Tooth profile code: \\
& & & 0 - Involute profile. \\
& & & \pm 1 - Conventional relief. \\
& & & \pm 2 - Optional tip relief. \\
8 & Al $^{2}$ & REAL & Normalized addendum, gear 1 \\
9 & A2 $^{2}$ & REAL & Normalized addendum, gear 2 \\
10 & Rfill $^{3}$ & REAL & Root fillet radius, gear 1, in. \\
11 & Rfil2 $^{3}$ & REAL & Root fillet radius, gear 2, in.
\end{tabular}

Notes:

1 An involute profile has no modification. Conventional modification provides linear tip relief, starting at the first transition point (ie: the length is 100\%). The amount of relief at the tip is equal to the tooth deflection. DANST solves the dynamic problem twice: First for unmodified teeth, then with any specified modification. The two solutions are needed to compute the dynamic load factor (defined as the peak dynamic load of modified gears divided by the peak static load of unmodified gears). Normally, plots are made for only the modified gears. You can also get plots for unmodified gears by entering a NEGATIVE number $(-1,-2)$ for Imod. Other tip relief parameters are specified in line 3. (See notes below.)

2 The tooth addendum is normalized by dividing by the diametral pitch. For standard low-contact-ratio gears, the addendum is 1/DP, hence, $\mathrm{Al}$ and $\mathrm{A} 2$ equal 1.0 . Values typically range from 0.80 for a stub tooth to 1.50 for a long-addendum tooth. See a gear design handbook for suggestions. You may wish to reduce the addendum value to account for edge break or gear diameter tolerance. If the addendum selected is too long (to make pointed teeth), DANST will print an error message and stop.

${ }^{3}$ You can either enter the actual root fillet radius or enter zero and DANST will default to a minimum value of $0.35 / \mathrm{P}_{\mathrm{d}}$. (This value is suggested in the Gear Handbook (Dudley, 1962).)
Line 3. Profile Modification ${ }^{1}$ (5 items reqd.)

\begin{tabular}{cccc} 
Item & Variable & Data type & Description \\
\hline 1 & ItMOD & INT & Type of modification: \\
& & 1 - linear. \\
& & 2 - parabolic type 1. \\
& & 3 - parabolic type 2. \\
& & 4 - digitized profile.
\end{tabular}

2 Pmodl $^{3}$ REAL - Length (start) on gear 1.

3 Pmod2 $^{3}$ REAL Length (start) on gear 2.

4 Amodl REAL Amount of modification on gear 1 , in.

5 Amod2 REAL Amount of modification on gear 2 , in.

Notes:

1 The data in this line will not be used unless Imod (in line 1) is 2. ("Dummy" values are still required.)

2 If linear or parabolic modification is specified, the length and amount of profile modification specified here will be used to modify tooth profiles. If a digitized profile is chosen, the data on lines 9 to 129 will be used for profile modifications. For parabolic type 1 modification, the trace on a profile chart has zero slope (tangent to involute) at the start of modification. For type 2, the trace has infinite slope (vertical) at the tooth tip. See Fig. 2 for a comparison of modification types.

${ }^{3}$ The length of modification may be expressed in either of 2 ways: (1) as percentage of the length from tooth tip to the first contact transition point on the gear. (For low-contact ratio gears, the first transition occurs at the highest point of single tooth contact. For highcontact-ratio gears, the first transition is the highest point of double tooth contact.) Alternately, (2) you may enter the roll angle (in degrees) at the start of modification. If option (2) is chosen, enter the value as a NEGATIVE number.

Line 4. Material Properties (4 items reqd.)

\begin{tabular}{clll} 
Item & Variable & Data type & Description \\
\hline 1 & E1 & REAL & Elastic modulus, gear 1, psi. \\
2 & E2 & REAL & Elastic modulus, gear 2, psi. \\
3 & Pois1 & REAL & Poisson's ratio, gear 1. \\
4 & Pois2 & REAL & Poisson's ratio, gear 2.
\end{tabular}

Line 5. Mass and Shaft Parameters (6 items reqd.)

Item Variable Data type Description

$1 \mathrm{JM}^{\mathrm{I}}$ REAL Motor inertia.

$2 \mathrm{Jl}^{1}$ REAL Gear $\mathrm{I}$ inertia.

$3 \mathrm{~J}^{1}$ REAL Gear 2 inertia.

$4 \Omega^{1}$ REAL Load inertia.

5 STIFF $1^{2}$ REAL Input shaft torsional stiffness.

6 STIFF2 $^{2}$ REAL Output shaft tors. stiffness.

Notes:

1 Mass moment of inertia is in units of lb-in- $\sec ^{2}$. 
2 Torsional stiffness is in units of $l b$-in/rad.

Line 6. System Solution Parameters (8 items reqd.)

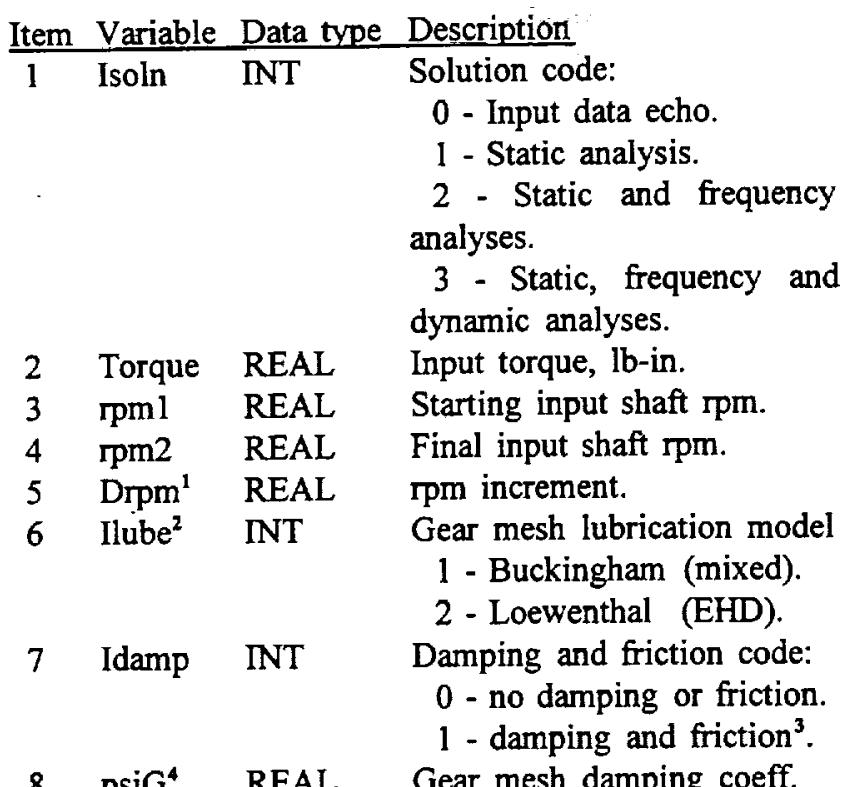

$8 \mathrm{psiG}^{4}$ REAL Gear mesh damping coeff.

Notes:

1 The maximum number of increments is 200 . The number of increments is: Ninc $=1+(\mathrm{rpm} 2-\mathrm{rpm} 1) / \mathrm{Drpm}$. If too many increments are requested, DANST will reduce Ninc to 200 by increasing Drpm.

2 Gear mesh lubrication depends on many parameters such as operating load, lubricant viscosity, surface roughness, etc. The authors of DANST generally use the Buckingham model for high-speed gears. Consult gear and lubrication literature for further information.

3 Including friction means the equations of motion include friction torques.

4 The mesh damping coefficient (fraction of critical) is typically 5 to $15 \%$, hence psiG is 0.05 to 0.15

Line 7. Print Request Codes ${ }^{1}$ (6 items reqd.)

\begin{tabular}{clll} 
Item & Variable & Data type & Description \\
\hline I & IWmod & INT & Print profile modifications. \\
2 & IWdefl & INT & Print tooth deflections. \\
3 & IWtERR & INT & Print static trans. error. \\
4 & IWdyLD & INT & Print dynamic tooth load. \\
5 & IWeFFT & INT & Print FFT of static trans. error. \\
6 & IWssLD & INT & $\begin{array}{l}\text { Print speed survey of dynamic } \\
\text { tooth loads. }\end{array}$
\end{tabular}

Notes:

1 If the value of request code is 1 the data will be printed to the output file (DANST.OUT). Otherwise, output will be suppressed.
Line 8. Plot Request Codes" (10 items reqd.)

\begin{tabular}{cll} 
Item & Variable & Data \\
\hline 1 & IPmod & INT \\
2 & IPdefl & INT \\
3 & IPteTL & INT \\
& & \\
& & \\
4 & IPeFFT $^{2}$ & INT \\
5 & IPcoF $^{2}$ & INT \\
6 & IPfTQ $^{2}$ & INT \\
7 & IPdyLD $^{2}$ & INT \\
8 & IPIFFT $^{2}$ & INT \\
9 & IPdynS $^{2}$ & INT \\
10 & IPspd & INT
\end{tabular}

Notes:

${ }^{1}$ If the value of request code is 1 the data will be plotted. If it is -1 output files (instead of plots) will be produced. These plot files have the same base name as the request code and with the extension ".DAT" for modified gears or ".UN" for unmodified gears (Example: SPD.DAT or SPD.UN). Any value other than \pm 1 for the code will suppress the output.

2 If plotted output is requested for friction coefficient, friction torque, dynamic load, dynamic stress, or FFT of dynamic load, there will be one set of plots for each speed (Ninc plots).

Lines 9-129. Digitized Profile (3 or 5 items per line)

\section{Item Variable Data type Description}

$\begin{array}{lll}1 & \text { RANerA REAL } & \text { Profile, tooth-pair A. } \\ 2 & \text { RANerB REAL } & \text { Profile, pair B. } \\ 3 & \text { RANerC REAL } & \text { Profile, pair C. } \\ 4 & \text { RANerD REAL } & \text { Profile, pair D (HCR only). } \\ 5 & \text { RANerE REAL } & \text { Profile, pair E (HCR only). }\end{array}$

Data lines 9 to 129 are used only for user-specified profile modifications (if ItMOD in line 3 is 4). Modification values are required for both the driver (gear 1) and follower (gear 2). These values must be provided for each of 121 contact positions. The contact positions are equally spaced (in terms of the roll angle) from the lowest to highest point of contact on a tooth. Hint: You can use DANST to find the required roll angles for you. Perform a static analysis for any of the standard profile options (such as unmodified involute) and "plot" profile charts to a file (set IPmod in line 8 to -1 ). The output file 'MOD.DAT' will contain the 121 roll angles for both driving and driven gears. 
The modification values represent the total deviation from the involute. (Add together any tip and root relief at each contact position.) DAN-MOD, a short BASIC computer program, can help produce the data required in lines 9-129. DAN-MOD is included on the distribution disk with DANST. Instructions are included with the program. Additional information is presented in Appendix B.

There are either three or five tooth pairs considered in the meshing process depending on whether the contact ratio is greater than 2.00. (The contact ratio can range from one to three.) This means that either 3 or 5 columns of modification data are required. Normally, the data in these 3 or 5 columns is identical. You can make them different to attempt to model errors.

\section{$\underline{\text { Test Cases }}$}

To demonstrate how to use DANST, we present three test cases. Each case involves gears tested on the NASA gear noise rig. An electric motor drives the rig through a belt drive speed-increaser and a soft coupling. A dynamometer produces resisting torque. Values for shaft stiffness, motor and load inertia (taken from manufacturers' specifications) are shown in table 1. (The motor inertia was computed by adding the inertias of the motor and the belt-drive pulley then, dividing by the square of the drive ratio.) Values suggested above were used for lubrication and damping parameters. Figs. 3 and 4 show portions of test gear drawings.

\section{Test Case I: 1:1 Spur Gears, Linear Tip Relief}

Consider a pair of standard low-contact-ratio spur test gears with the dimensions shown in Fig. 3. Table 2 gives basic data for the gears. For this example, the addenda were not corrected to account for the edge break or for tolerance on the outside diameter of the gears. The theoretical contact ratio (calculated by DANST) is 1.64. The gear inertia was calculated assuming the gears to be solid steel disks equal to the pitch diameter then adding the inertia of the hubs. No allowance was made for the gear shaft inertia.

These gears have linear tip relief with a total amount (at the tooth tip) of 0.0007 in. and starting at a roll angle of 24 degrees. (This length of modification represents about $90 \%$ of the distance from tooth tip to high point of single tooth contact.)

The input data file for this example is shown below. The lines marked (a) are for a single-speed analysis, the lines marked (b) are for a speed survey.

Test Case I - Gear Noise Test Gears

$\begin{array}{lllllllllll}28 & 28 & 8.0 & 20.0 & 0.25 & .010 & 2 & 1.0 & 1.0 & .050 & 050\end{array}$ $\begin{array}{lrrrr}1 & -24.0 & -24.0 & 0.0007 & 0.0007\end{array}$

$30 . E+06 \quad 30 . E+06 \quad 0.30 \quad 0.30$

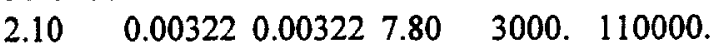

$\begin{array}{lllllll}\text { (a) } 3 & 635.6000 .6000 . & 00 . & 1 & 1 & 0.10\end{array}$

(b) 3 635. 2000.12000. 100.110 .10

$\begin{array}{llllll}0 & 0 & 0 & 0 & 0 & 0\end{array}$

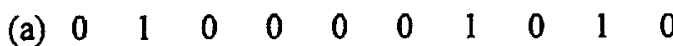

(b) $0 \begin{array}{llllllllll} & 0 & 0 & 0 & 0 & 0 & 0 & 0 & 0 & 1\end{array}$

The three plots for this example are shown in Figs. 5(a) to 5(c). This is a single speed analysis at $6000 \mathrm{rpm}$ and $635 \mathrm{lb}$-in torque. By changing only a few data items (substituting the lines marked (b) for those marked (a)), we have a speed-survey from $2000-12000 \mathrm{rpm}$ at the same torque. The speed-survey analysis results are shown in Fig. 5(d).

\section{Test Case II: Spur Gears, Parabolic Type 2 Tip Relief}

This is similar to test case 1(a), except for the type of tip relief and output requests. Results from a parameter study (46 individual computer runs) of the amount and length of tip relief are shown in Fig. 6. This was made by a separate plotting program. The example data file below produced the data point in Fig. 6 with the lowest dynamic load.

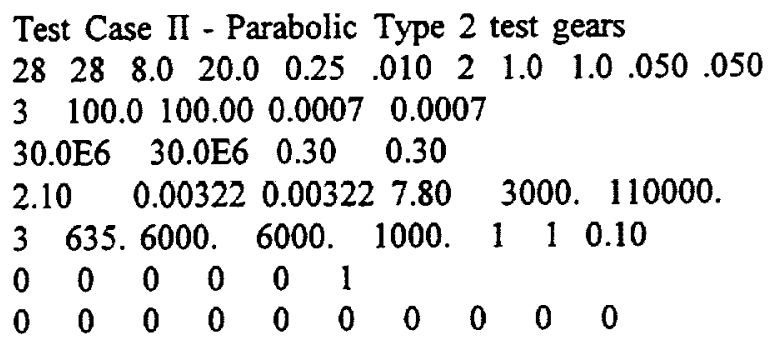

Test Case III: 25:31 HCR gears, Digitized Profile

This case involves high-contact-ratio spur test gears with dimensions shown in Fig. 4. Basic data for the gears are given in Table 3. These gears have profile relief on both the addendum and dedendum (see Fig. 7) and do not fit any of the standard profiles included in the program. This means the profile data must be entered as digital values for lines 9-129 of the input file. Profile values estimated from these traces are listed in table 4 . These estimated values were used with the auxiliary program DAN-MOD to produce the profile modifications needed for lines 9-129. (Only the first 2 and last 2 of these 121 lines of modification data are shown below.) Appendix $B$ presents more information on using DAN-MOD.

We subtracted $-.00075 \mathrm{in}$. from the gear addendum to account for one half of the average tolerance on the outside diameter of the gear. (Note: We divide by two because the addendum is a radius value.) We also subtracted 0.015 in. from the addendum. This is the average of the max. and min. edge break. The addendum 
corrections reduce the theoretical contact ratio from 2.15 to 2.04 .

To estimate the gear inertia, we assumed the gears to be solid steel disks equal to the pitch diameter. We subtracted a correction from the gear inertia to account for the web-rim structure. We made no allowance for gear shaft inertia. Computed static and dynamic loads for this case are plotted in Fig. 8.

Test Case III - Baseline HCR Spur Gears 9/15

$\begin{array}{lllllllllll}25 & 31 & 8.0 & 20.0 & 1.25 & 0075 & 2 & 1.336 & 1.256 & 050 & 050\end{array}$

4 0. 0.0 .0 .0$.

30.E6 $30 . \mathrm{E} 6 \quad 0.3 \quad 0.3$

$\begin{array}{llllll}7.2 & 8.43 \mathrm{E}-3 & 16.1 \mathrm{E}-3 & 7.80 & 3000 . & 110000 .\end{array}$

$\begin{array}{llllllll}3 & 2269.0 & 3000 . & 3000 . & 1000 . & 1 & 1 & 0.1\end{array}$

$0 \begin{array}{llllll}0 & 0 & 0 & 0 & 0 & 1\end{array}$

$\begin{array}{llllllllll}0 & 0 & 0 & 0 & 0 & 0 & 1 & 0 & 0 & 0\end{array}$

7.584E-04,7.584E-04,7.584E-04,7.584E-04,7.584E-04

7.529E-04,7.529E-04,7.529E-04,7.529E-04,7.529E-04

... [117 lines omitted] ...

9.385E-04,9.385E-04,9.385E-04,9.385E-04,9.385E-04

9.476E-04,9.476E-04,9.476E-04,9.476E-04,9.476E-04

\section{Validation Studies for DANST}

A study to validate the DANST code compared analytical results with experimentally measured values of tooth load and stress (Oswald et al., 1991 and Rebbechi, et al., 1991). Figure 9 (extracted from the reference) compares peak values of dynamic stress from analysis and experiment. In general, the predicted stress in Fig. 9 is 10 to 15 percent less than the measured stress although the predicted forces (not shown here) were generally within five percent of measured values.

In Oswald et al., 1991, the difference in stress results between analysis and experiment was attributed to underestimating stress sensitivity. To investigate whether DANST correctly estimated the stress, we conducted a finite element study. A two-dimensional plane-stress finite element model, shown in figure 10 , was used to calculate the maximum fillet stresses. This involved a series of analyses in which a unit load, directed along the line of action, was applied in sequence to each node along the active profile. Because the finite element analysis is linear, we scaled the unit load stress values by the corresponding dynamic loads predicted by DANST to arrive at finite element method (FEM) dynamic stress values for a tooth meshing cycle.

Figure 11 shows a comparison of strain gage, FEM and DANST values for tooth bending stress for the gears of Test Case I. The calculated DANST stress values closely track (six percent less at the peak stress) the FEM stress values. This indicates the DANST stress sensitivity estimate is reasonable. However, the measured (strain gage) stress values are considerably higher than the FEM predictions. The difference is eighteen percent for the peak stress in Fig. 11.

\section{Appendix A: Installation Information}

DANST was written in ANSI standard FORTRAN 77 and should run on any mainframe computer with a standard FORTRAN 77 compiler. The optional graphical output requires commercially available DI- 3000 graphics library routines. Users without access to DI-3000 who wish to use the analysis can follow instructions below to delete the graphics portions of the program. DANST can generate files for a separate plotting program.

The file DANST.FOR contains the FORTRAN source code (about 6000 lines) for DANST. The file includes a main program and 45 subroutines. At the beginning of the source code listing is a description for each subroutine and its calling sequence. The source code must be copied to your computer system, compiled and linked. Names for input, output and temporary datafiles built into the program follow the VAX naming convention. Users of some other systems may need to change these names.

Input/output files used by DANST are shown below:

unit 4 -- Input datafile (DANST.IN)

unit * -- Interactive input (keyboard)

unit * -- Interactive output (display)

unit 7 -. Output datafile (DANST.OUT)

unit 3 -- Optional graphics output datafiles (*.DAT)

unit 1 -- Temporary datafile (TEMP.DAT)

To remove the graphics portions of DANST, do the following:

(1) Delete the GRAPHICS subroutines and statements in the file DANST.FOR by removing 21 graphics blocks from the program. To help you in this process, the beginning and end of each graphics block is marked with comments such as:

C $\gg>$ DI-3000 graphics start $\ll<$ [ Block-1 ]

C $\gg$ DI-3000 graphics end $\ll$ [Block-1]

Remove everything between the beginning and end markers. (Hint: Look for the string "〉> DI-3000".) The end of the last block is the end of the source code file. (The last block is not marked because some compilers generate an error message if there is a comment at the end of the file.)

(2) Compile and run the revised DANST.FOR from above. This will leave the analysis portion of the program. You can use your own graphics program to plot output data files. 


\section{Appendix B: Using DAN-MOD for Digitized Profile}

DAN-MOD is a short auxiliary program to help generate the modification data required for the digitized profile option in DANST. DANST requires 121 values for any deviations from involute profile taken at equal intervals of roll angle between the highest and lowest points of tooth contact. DAN-MOD can interpolate (and extrapolate if necessary) to provide this data.

To begin the process, we use the data in Table 4 to produce two data files. The first two columns of the table contain the modification data for the pinion (suggested file name PROFILE.1) The roll angle and modification values must be separated by commas. (For our example, the first line contains "5, .00039"). The last two columns of Table 4 contain similar data for the gear (PROFILE.2). Note: The profile data for DAN-MOD need not be evenly spaced. You can add or eliminate points as needed. DAN-MOD uses linear interpolation on the data you supply.

DAN-MOD requires a third input datafile (suggested name DAN-ROLL) which contains 121 pairs of roll angles for the gears. DANST can produce this data as follows: Use an input file such as for test case III with four changes: (1) For Imod (item seven in line two) replace "2" with "0" (involute profile); (2) For Isoln (item one in line six) change "3" to "1" (static analysis); (3) In line eight, set IPmod (item one) to "-1" (plot to file) and the other nine items to "0"; (4) No data is required for lines 9-129. (This data is not yet known.) DANST can use this file to produce an output "plot" file named MOD.DAT. With a text editor, delete heading lines and two columns of modification data leaving only the roll angles in 121 lines and two columns. The columns must be separated by commas. (For example "6.307, 32.585" forms the first line for test case III.) This is the data for the DAN-ROLL file.

Next run DAN-MOD using the three input files discussed above. The result is a file containing the modification data needed for lines 9-129 of the DANST input file. A portion (first 2 and last 2 lines) of this datafile is shown in the discussion for test case III. DAN-MOD also plots a modification trace to the computer screen.

\section{$\underline{\text { References }}$}

Boyd, L.S., and Pike, J.A., 1987, "Expansion of Epicyclic Gear Dynamic Analysis Program," Contractor Report HSER-10853, Hamilton Standard, Windsor Locks, CT, NASA Contract NAS3-24614, NASA CR-179563

Dudley, Darle W., editor, 1962, Gear Handbook, McGraw-Hill Book Co, NY.
Kahraman, A., Ozguven, H.N., Houser, D.R., and Zakrajsek, J.J., 1990, "Dynamic Analysis of Geared Rotors by Finite Elements," NASA-TM-102349.

Lee, C, Lin, H.H., Oswald, F.B., and Townsend, D.P., 1991, "Influence of Linear Profile Modification and Loading Conditions on the Dynamic Tooth Load and Stress of High Contact Ratio Gears," J. of Mech. Design, Vol 113, No. 4.

Lin, H.H., Lee, C., Oswald, F.B. Townsend, D.P., 1993, "Computer-Aided Design of High-Contact-Ratio Gears for Minimum Dynamic Load," J. of Mechanical Design, Vol 115, No. 1.

Lin, H.H., Townsend, D.P., and Oswald, F.B., 1989a, "Dynamic Loading of Spur Gears with Linear or Parabolic Tooth Profile Modifications," Proc. of ASME 5th Int. Power Trans. and Gearing Conf., Chicago, Illinois, Vol. 1, pp. 409-419.

Lin, H.H., Oswald, F.B., and Townsend, D.P., 1989b, "Profile Modification to Minimize Spur Gear Dynamic Loading," Proc. of ASME 5th Int. Power Trans. and Gearing Conf., Chicago, Illinois, Vol. 1, pp. 455-465.

Lin, H.H., Huston, R.L., and Coy, J.J., 1988a, "On Dynamic Loads in Parallel Shaft Transmissions: Part I Modeling and Analysis," ASME Trans., J. of Mechanisms, Transm. and Automation in Design, Vol. 110 , No. 2, pp. 221-225.

Lin, H.H., Huston, R.L., and Coy, J.J., 1988b, "On Dynamic Loads in Parallel Shaft Transmissions: Part II Parameter Study," ASME Trans., J. of Mechanisms, Transm. and Automation in Design, Vol. 110, No. 2, pp. 226-229.

Lin, H.H., and Huston, R.L., 1986, "Dynamic Loading on Parallel Shaft Gears," NASA CR-179473

Liou, C-H., Lin, H.H., Oswald, F.B., Townsend, D.P., 1992, "Effect of Contact Ratio on Spur Gear Dynamic Load," Proc. of ASME 6th Int. Power Trans. and Gearing Conf., Phoenix, AZ, Vol. 1, pp. 29-33.

Oswald, F.B., Rebbechi, B., Zakrajsek, J.J., Townsend, D.P., and Lin, H.H., 1991, "Comparison of Analysis and Experiment for Dynamics of Low-ContactRatio Spur Gears," ASME 13th Biennial Conference on Mechanical Vibration and Noise, Miami, FL, NASA TM-103232

Pike, J.A., 1981, "Interactive Multiple Spur Gear Mesh Dynamic Load Program," NASA CR-165514.

Zakrajsek, J.J., Oswald, F.B., Townsend, D.P., and Coy, J.J., 1990, "Gear Noise, Vibration, and Diagnostic Studies at NASA Lewis Research Center," First International Conference on Gearbox Noise and Vibration, University of Cambridge, England, Apr. 9-11, 1990, pp. 27-34 
TABLE 1 - Gear Noise Rig Parameters

\begin{tabular}{|l|l|}
\hline Mass inertia, Motor & $2.1 \mathrm{lb}-i n-\mathrm{sec}^{2}$ \\
\hline Mass inertia, dynamometer & $7.8 \mathrm{lb}-i n-\mathrm{sec}^{2}$ \\
\hline Stiffness, driving shaft & $3000 \mathrm{lb}$-in/radian \\
\hline Stiffness, driven shaft & $110,000 \mathrm{lb}-$ in/radian \\
\hline
\end{tabular}

TABLE 2 - Gear Data, Test Cases I and II

\begin{tabular}{||l|l|}
\hline Number of teeth & 28 \\
\hline Diametrial pitch & $8 \mathrm{in}^{-1}$ \\
\hline Face width & $0.25 \mathrm{in}$ \\
\hline Backlash & $0.010 \mathrm{in}$ \\
\hline Tooth addendum & $1.00 / \mathrm{DP}$ \\
\hline Young's modulus & $30 * 10^{6} \mathrm{psi}$ \\
\hline Poisson's ratio & 0.30 \\
\hline Mass inertia & $0.00322 \mathrm{lb}^{-i n-s e c}{ }^{2}$ \\
\hline Lubrication model & Buckingham \\
\hline Mesh damping coefficient & $0.10(10 \%$ of critical) \\
\hline
\end{tabular}

TABLE 3 - Gear Data, Test Case III

\begin{tabular}{||l|l|}
\hline Number of teeth & 25 and 31 \\
\hline Diametrial pitch & $8 \mathrm{in}^{-1}$ \\
\hline Face width & 1.25 in \\
\hline Backlash & 0.0075 in \\
\hline Outside diameter & 3.4905 and 4.2205 in \\
\hline Young's modulus & $30 * 10^{6}$ psi \\
\hline Poisson's ratio & 0.30 \\
\hline Mass inertia & $\begin{array}{l}0.0843 \text { and } 0.0161 \\
\text { lb-in-sec }\end{array}$ \\
\hline Lubrication model & Buckingham \\
\hline $\begin{array}{l}\text { Mesh damping } \\
\text { coefficient }\end{array}$ & 0.10 (10\% of critical) \\
\hline
\end{tabular}

TABLE 4 - Modification Data for Test Case III (estimated from profile plots)

\begin{tabular}{|c|c|c|c|}
\hline Roll angle & $\begin{array}{l}\text { Modif. } \\
\text { Pinion, in }\end{array}$ & Roll angle & $\begin{array}{l}\text { Modif. } \\
\text { Gear, in }\end{array}$ \\
\hline 5 & .00039 & 8 & .00055 \\
\hline 6 & .00037 & 9 & .00051 \\
\hline 7 & .00033 & 10 & .00046 \\
\hline 8 & .00028 & 11 & .00042 \\
\hline 9 & .00022 & 12 & .00041 \\
\hline 10 & .00018 & 13 & .00036 \\
\hline 11 & .00016 & 14 & .00030 \\
\hline 12 & .00010 & 15 & .00025 \\
\hline 13 & .00007 & 16 & .00020 \\
\hline 14 & .00007 & 17 & .00016 \\
\hline 15 & .00007 & 18 & .00007 \\
\hline 16 & .00006 & 19 & .00001 \\
\hline 17 & .00005 & 20 & 0 \\
\hline 18 & .00005 & 20.85 & 0 \\
\hline 19 & .00004 & 21 & .00001 \\
\hline 20 & .00002 & 22 & .00001 \\
\hline 20.85 & 0 & 23 & .00004 \\
\hline 21 & 0 & 24 & .00004 \\
\hline 22 & .00001 & 25 & .00007 \\
\hline 23 & .00003 & 26 & .00009 \\
\hline 24 & .00004 & 27 & .00012 \\
\hline 25 & .00003 & 28 & .00017 \\
\hline 26 & .00003 & 29 & .00020 \\
\hline 27 & 0 & 30 & .00025 \\
\hline 28 & .00001 & 31 & .00030 \\
\hline 29 & .00003 & 32 & .00038 \\
\hline 30 & .00007 & 32.50 & .00040 \\
\hline 31 & .00014 & & \\
\hline 32 & .00024 & & \\
\hline 33 & .00029 & & \\
\hline 34 & .00032 & & \\
\hline 35 & .00036 & & \\
\hline 36 & .00046 & & \\
\hline
\end{tabular}




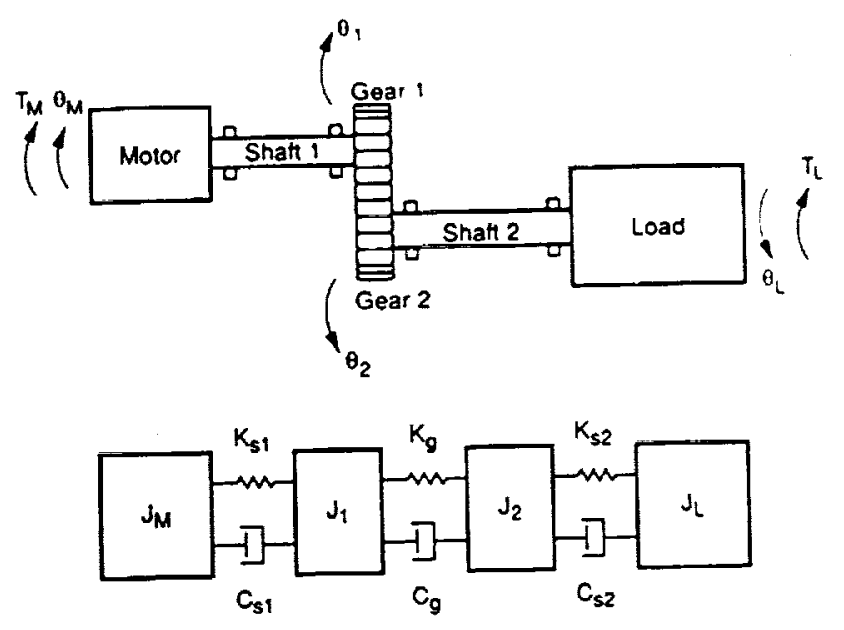

Figure 1 - Spur gear system model.

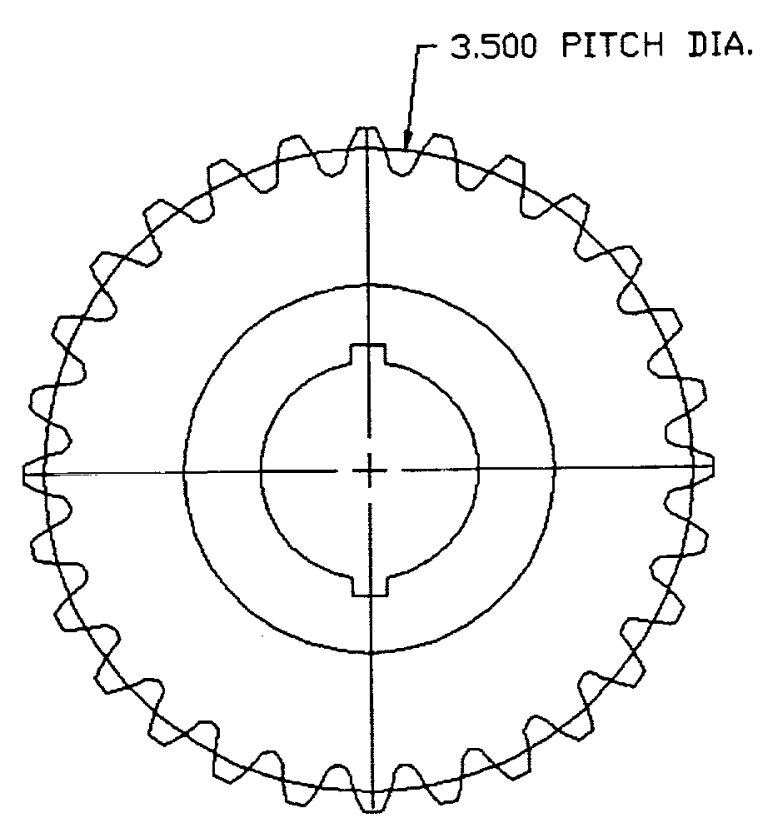

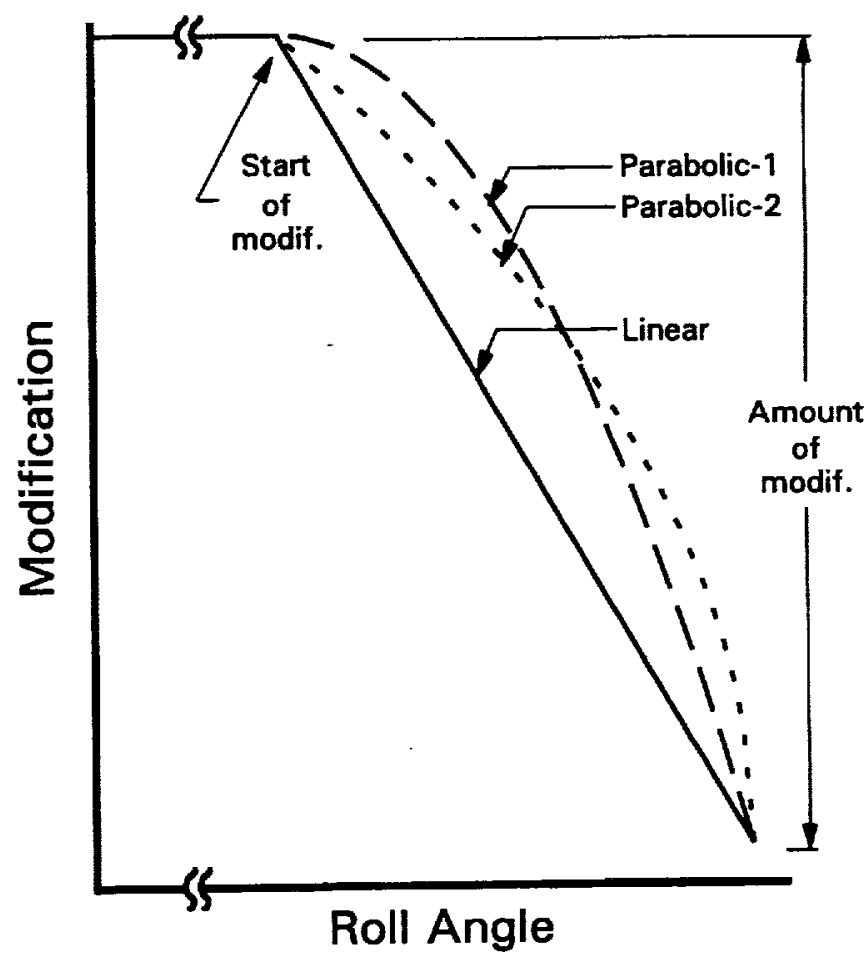

Figure 2 - Three types of tip relief: Linear, Parabolic Type-1, Parabolic type-2.

Figure 3 - Drawings for NASA test gears (test cases I and II). 


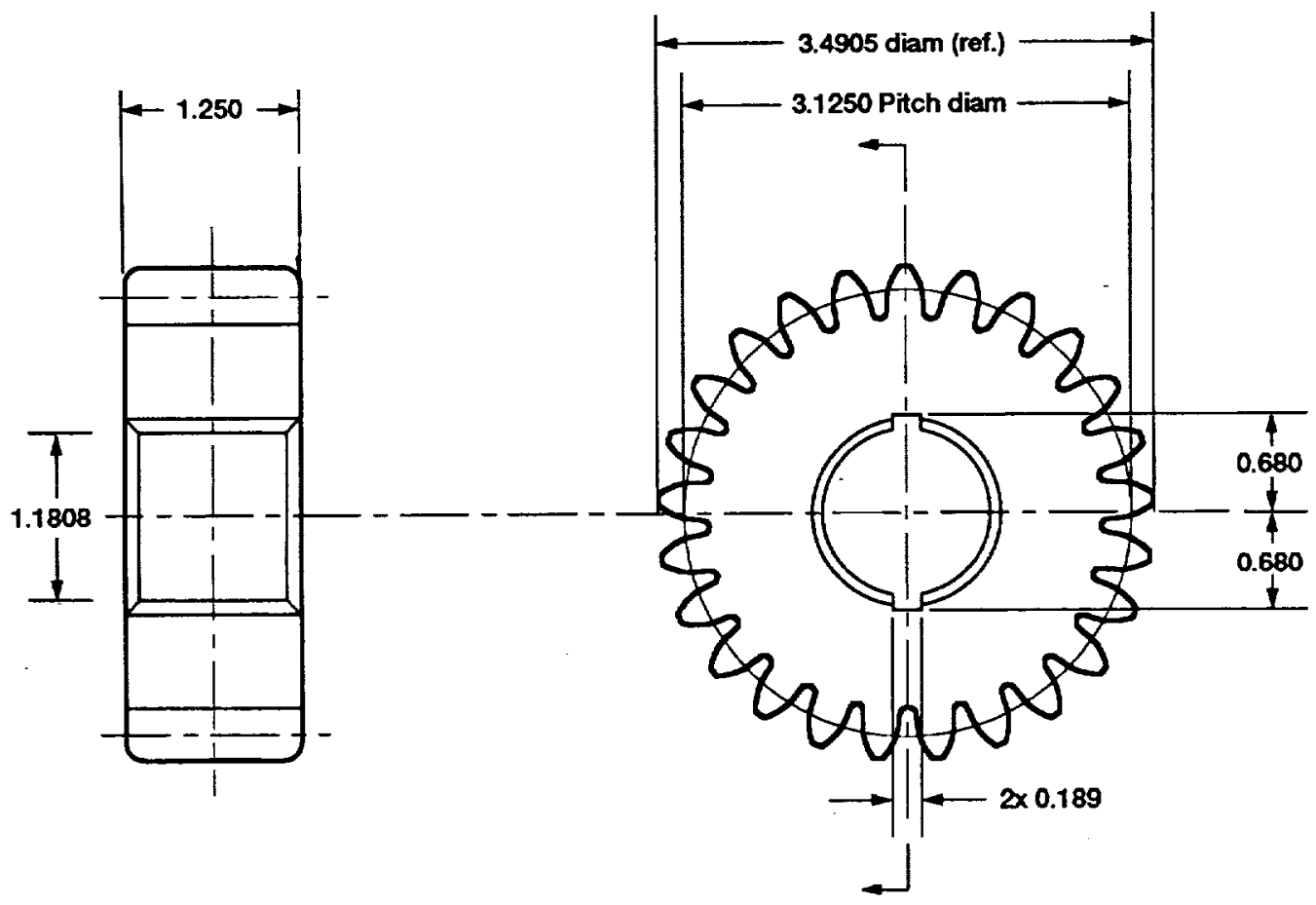

(a) Pinion, 25 teeth.

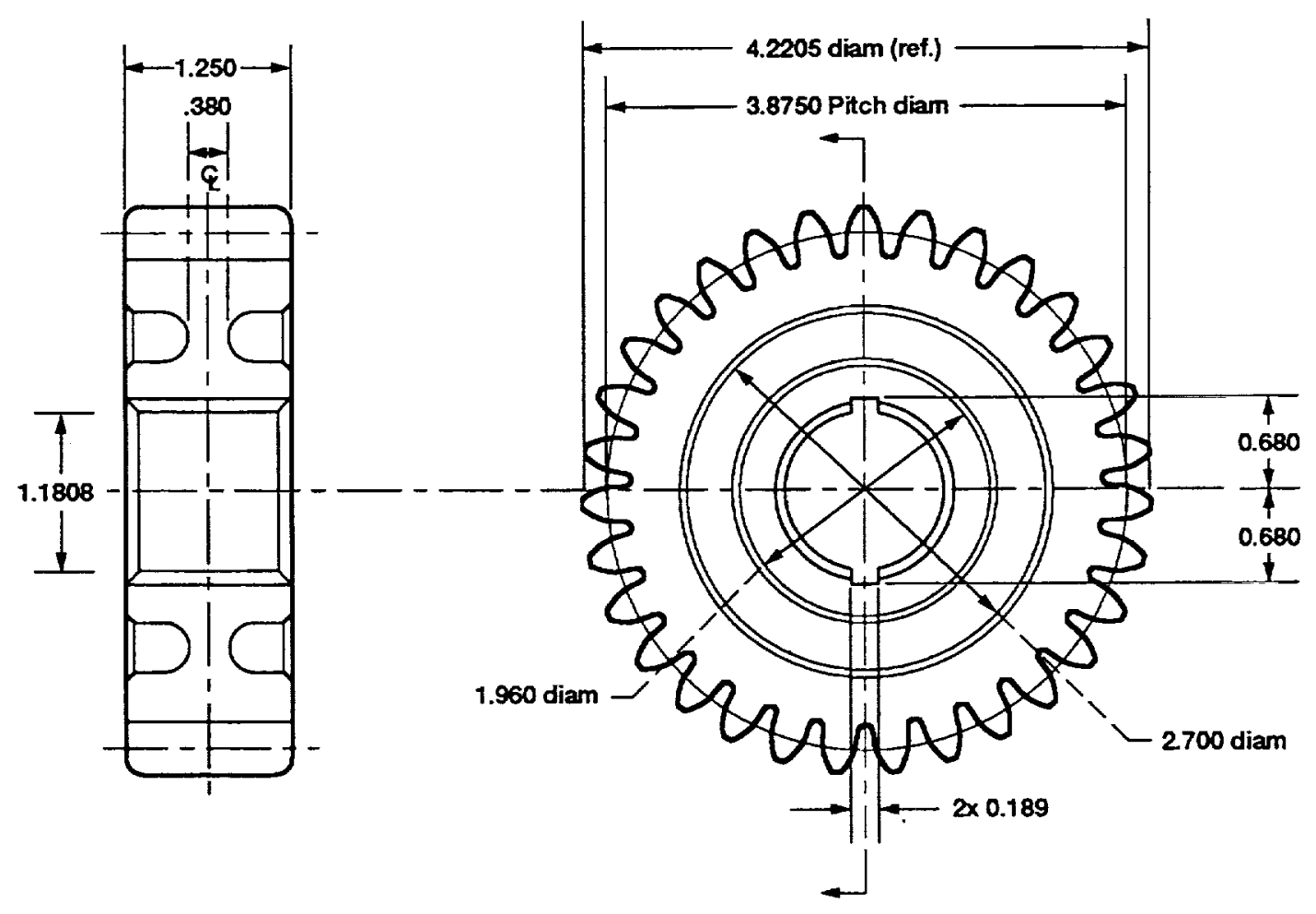

(b) Gear, 31 teeth.

Figure 4 - Drawings for high contact ratio gears (test case III). 


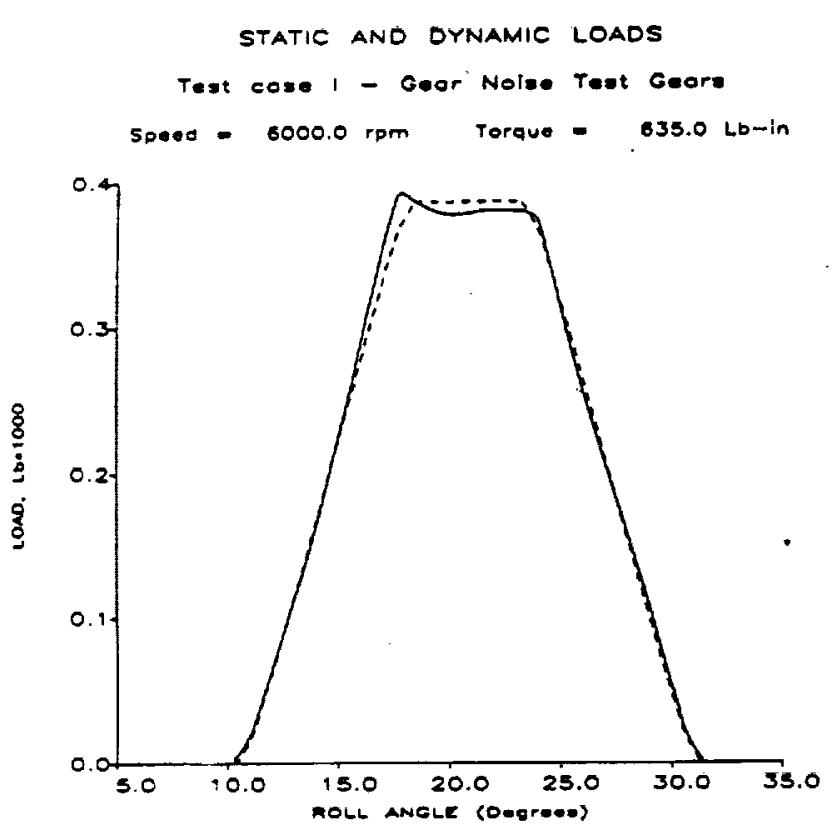

(a) Static and dynamic tooth loads: Dashed line static load; Solid line - dynamic load.

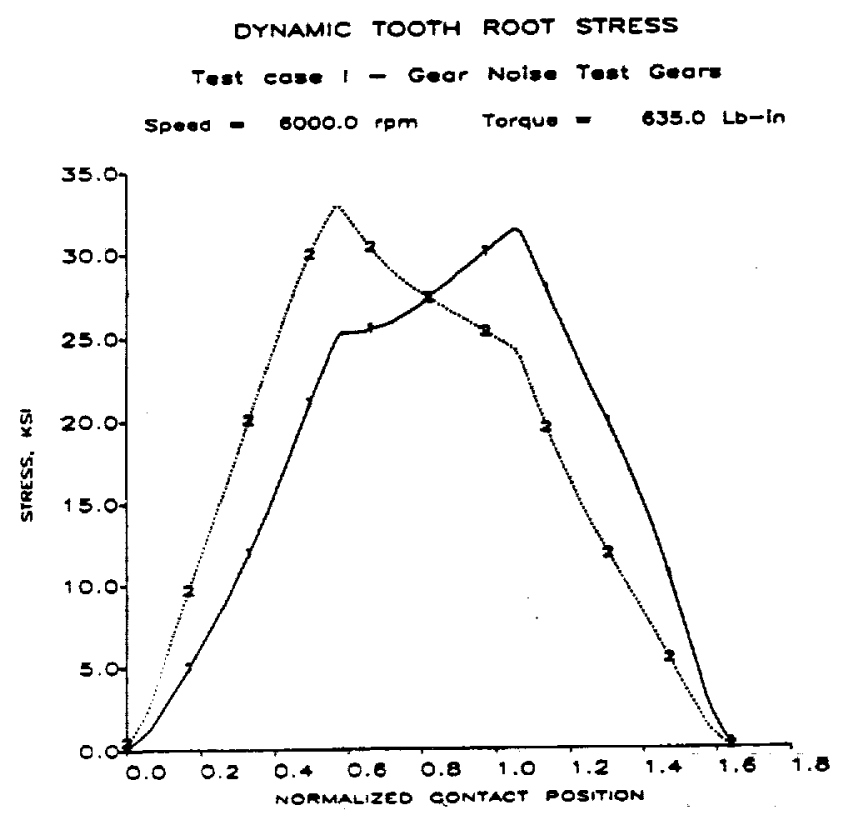

(c) Dynamic tooth root stress: Line marked ' 1 ' is for gear 1; Line marked ' 2 ' is for gear 2.

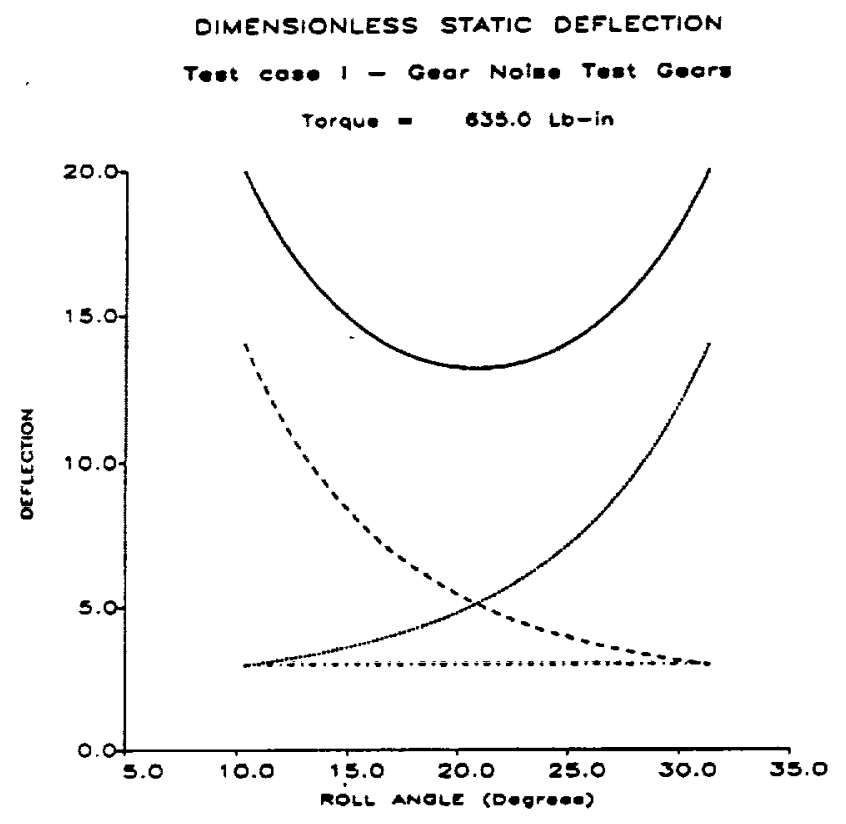

(b) Static deflection: Bottom line - Hertzian deflection; Line rising from left - bending deflection of gear 1; Line rising from right bending deflection of gear 2; Top line - total deflection.

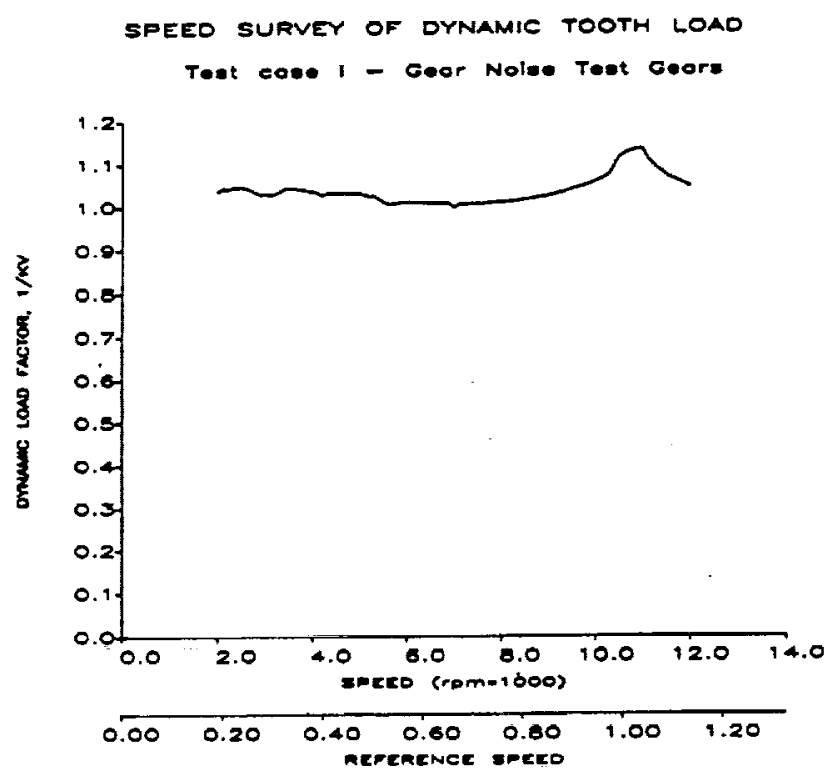

(d) Speed survey of dynamic tooth load in terms of dynamic factor (defined as max. dynamic load divided by max. static load).

Figure 5 - Graphical output from Test Case I. 


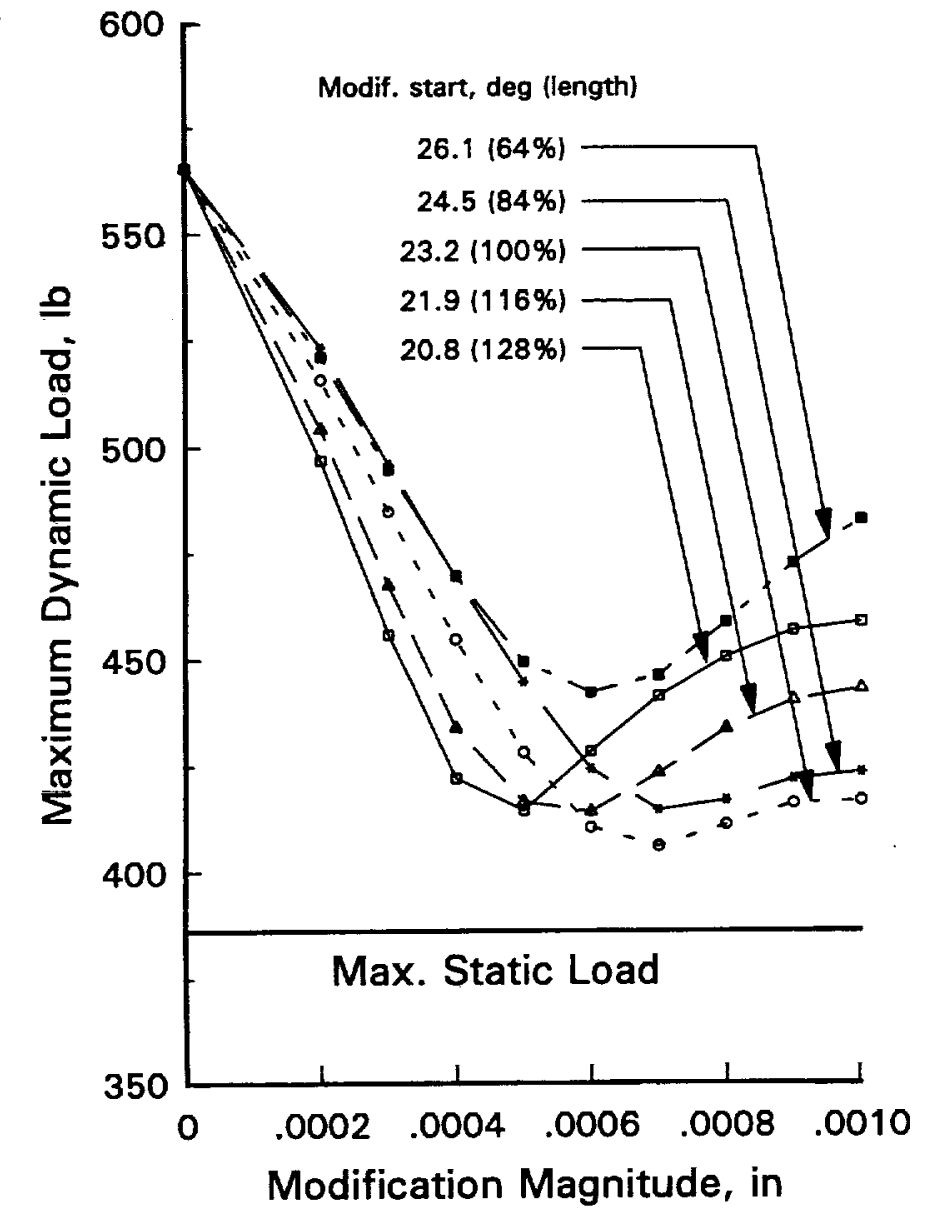

Figure 6 - Parameter study (test case II).

The various curves are labeled according to the starting point (degrees of roll angle) for tip modification and for the length of modification where $100 \%$ represents starting at high point of single tooth contact.

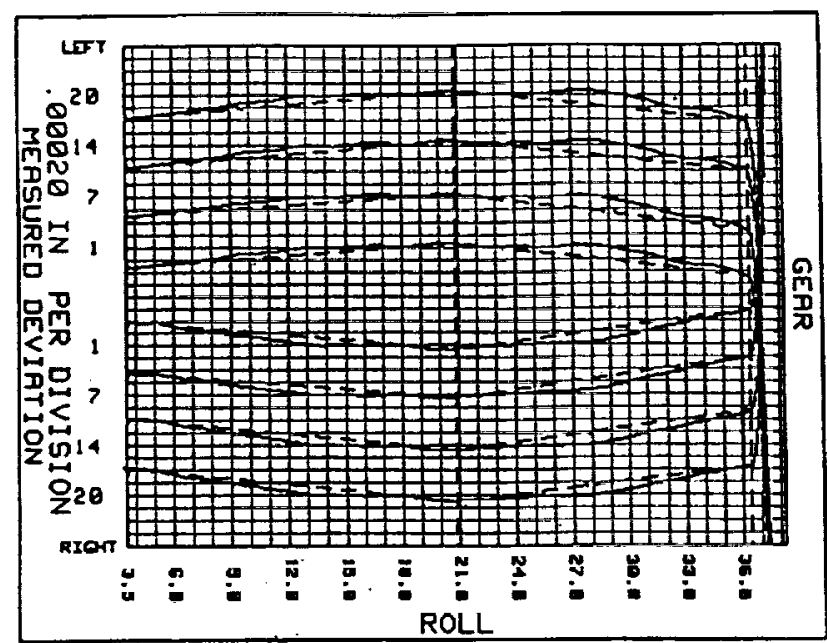

(a) Pinion, 25 teeth.

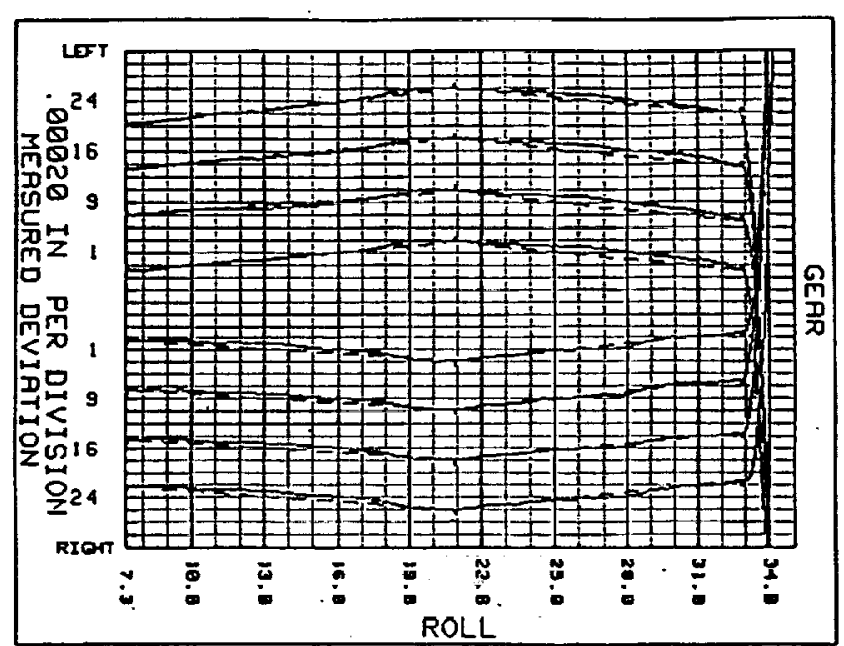

(b) Gear, 31 teeth.

Figure 7 - Profile traces for high contact ratio gears (test case III). 


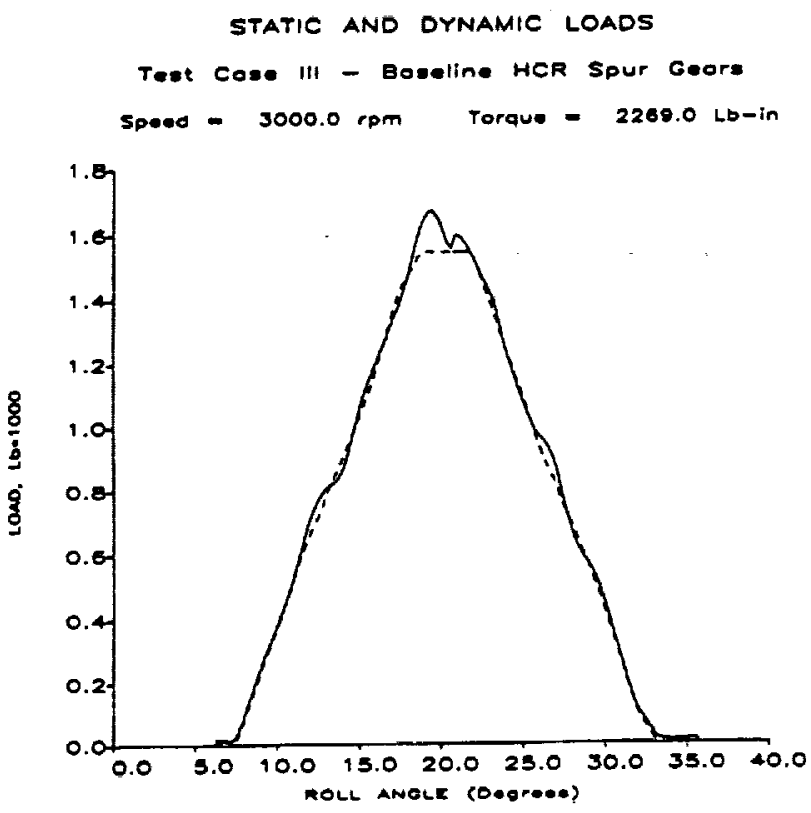

Figure 8 - Graphical output from test case III:

Static and dynamic tooth loads: Dashed line - static load; solid line - dynamic load.
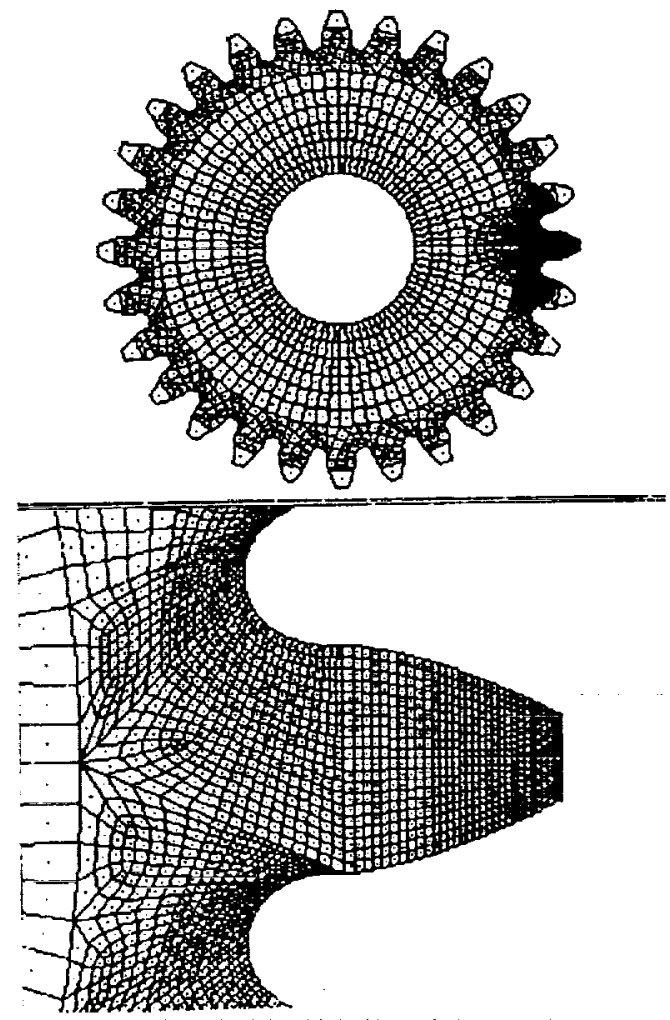

Figure 10 - FEM model of NASA test gears.

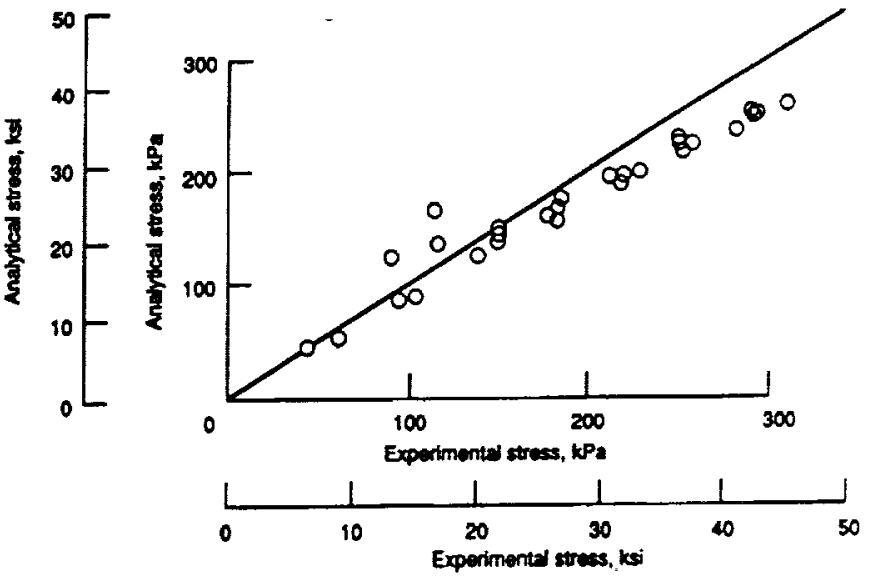

Figure 9 - DANST predictions for peak stress compared to experimental data.

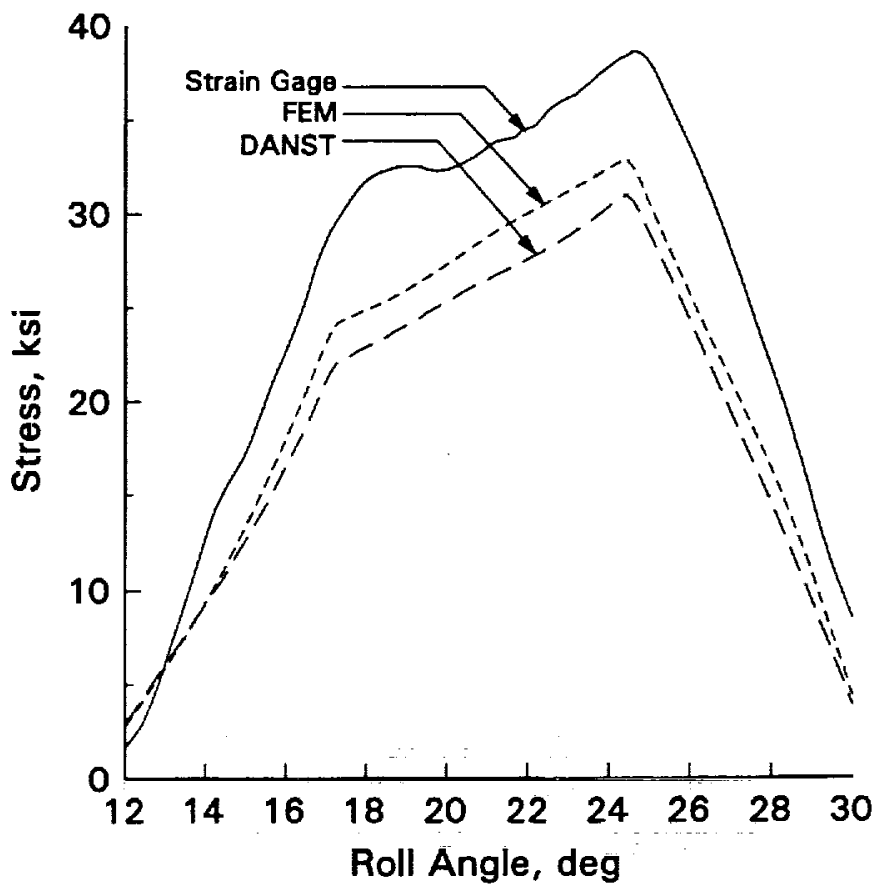

Figure 11 - Comparison of DANST stress predictions with FEM stress (based on DANST load) and with measured (strain gage) stress. 
Public reporting burden for this collection of information is estimated to average 1 hour per response, including the time for reviewing instructions, searching existing data sources, gathering and maintaining the data needed, and completing and reviewing the coliection of information. Send comments regarding this burden estimale or any other aspecl of this collection of information, including suggestions for reducing this burden, to Washington Headquarters Services, Directorate for intormation Opertion (0704-0188), Washington, DC 20503.

\begin{tabular}{l|l|l|} 
Davis Highway, S. REPORT TYPE AND DATES COVERED \\
\hline
\end{tabular}

\begin{tabular}{l|r|r|r|} 
T. AGENCY & Technical Memorandum \\
\hline
\end{tabular}

4. TITLE AND SUBTITLE

Dynamic Analysis of Spur Gears Using Computer Program DANST

5. FUNDING NUMBERS

6. AUTHOR(S)

.WU-505-62-10

1L162211A47A

Fred B. Oswald, Hsiang Hsi Lin, Chuen-Huei Liou, and Mark J. Valco

7. PERFORMING ORGANZATION NAME(S) AND ADDRESS(ES)

NASA Lewis Research Center

Cleveland, Ohio 44135-3191

and

Vehicle Propulsion Directorate

U.S. Army Research Laboratory

Cleveland, Ohio 44135-3191

9. SPONSORING/MONITORING AGENCY NAME(S) AND ADDRESS(ES)

National Aeronautics and Space Administration

Washington, D.C. 20546-0001

and

U.S. Army Research Laboratory

Adelphi, Maryland 20783-1145

8. PERFORMING ORGANRATION REPORT NUMBER

E-7921

11. SUPPLEMENTARY NOTES

Prepared for the 29th Joint Propulsion Conference and Exhibit cosponsored by the AIAA, SAE, ASME, and ASEE, Monterey, California,

June 28-30, 1993. Fred B. Oswald, NASA Lewis Research Center, Cleveland, Ohio; Hsiang Hsi Lin and Chuen-Huei Liou, Memphis State

University, Memphis, Tennessee 38152; and Mark J. Valco, Vehicle Propulsion Directorate, U.S. Army Research Laboratory, Lewis

Research Center, Cleveland, Ohio 44135. Responsible person, F.B. Oswald, (216) 433-3957.

12a. DISTRIBUTION/AVAILABILTY STATEMENT

12b. DISTRIBUTION CODE

Unclassified - Unlimited

Subject Category 37

\section{ABSTRACT (Maximum 200 words)}

DANST is a computer program for static and dynamic analysis of spur gear systems. The program can be used for parametric studies to predict the effect on dynamic load and tooth bending stress of spur gears due to operating speed, torque, stiffness, damping, inertia, and tooth profile. DANST performs geometric modeling and dynamic analysis for low- or high-contact-ratio spur gears. DANST can simulate gear systems with contact ratio ranging from one to three. It was designed to be easy to use and it is extensively documented by comments in the source code. This report describes the installation and use of DANST. It covers input data requirements and presents examples. The report also compares DANST predictions for gear tooth loads and bending stress to experimental and finite element results.

\section{SUBJECT TERMS}

Spur gears; Dynamic load; Profile modification; Stress

15. NUMBER OF PAGES $14:$

16. PRICE CODE $\mathrm{A} 03$.

17. SECURITY CLASSIFICATION OF REPORT

Unclassified
19. SECURITY CLASSIFICATION OF ABSTRACT Unclassified 
